\title{
Hepatic Glucagon Metabolism

\author{
Correlation of Hormone Processing by Isolated Canine Hepatocytes \\ with Glucagon Metabolism in Man and in the Dog
}

\author{
William A. Hagopian and Howard S. Tager \\ Department of Biochemistry and Molecular Biology, The University of Chicago, Chicago, Illinois 60637
}

\begin{abstract}
We have found that canine and rat hepatocytes convert ${ }^{125}$ I)iodoTyr ${ }^{10}$-glucagon to a peptide metabolite lacking the $\mathrm{NH}_{2}$-terminal three residues of the hormone. The peptide is released into the cell incubation medium and its formation is unaffected by a variety of lysosomotropic or other agents. Use of specific radioimmunoassays and gel filtration demonstrated in both normal subjects and in chronic renal failure patients a plasma peptide having the properties of the hormone fragment identified by cell studies. Studies of the dog revealed a positive gradient of the fragment across the liver and no differential gradient of the fragment and glucagon across the kidney. We conclude that $(a)$ the glucagon fragment arises from the cell-mediated processing of the hormone on a superficial aspect of the hepatocyte, $(b)$ the glucagon fragment identified during experiments in vitro represents the cognate of a peptide formed during the hepatic metabolism of glucagon in vivo, and (c) measurement of the fragment by $\mathrm{COOH}$-terminal radioimmunoassays could lead to an understimulation of hepatic glucagon extraction.
\end{abstract}

\section{Introduction}

The metabolism of peptide hormones by hormone-sensitive tissues represents a process important both to terminating the effector signal and to maintaining appropriate levels of the effector in the circulation. The liver, in fact, plays a crucial role in the tissue extraction of the pancreatic hormones insulin and glucagon (hepatic extraction of the two hormones being 45 and 23\%, respectively, ref. 1) and accounts for a major fraction of the rapid metabolic clearance of these regulatory peptides (2). While the renal clearance of peptide hormones generally occurs largely by receptor-independent mechanisms (2), hepatic mechanisms for peptide hormone metabolism are known to be specific for each effector and to require the prior binding of ligand to plasma membrane receptors (3-5). Studies of receptor-mediated hormone metabolism can thus provide important clues that clarify how ligand-receptor complexes are processed after the appropriate hormone signal has been transduced, as well as how cellular events modify the levels of bioactive hormone in the circulation. The cellular metabolism of insulin by isolated hepatocytes and adipocytes has been studied in detail with the result that both lysosomal mechanisms (as assessed by use of various

\footnotetext{
Address reprint requests to Dr. Tager. 1986.

Received for publication 23 May 1986 and in revised form 3 September
}

J. Clin. Invest.

(C) The American Society for Clinical Investigation, Inc.

0021-9738/87/02/0409/09 \$1.00

Volume 79, February 1987, 409-417 pharmacological agents and by electron microscopic autoradiography, ref. 6-8) and extralysosomal mechanisms (as assessed by use of cellular fractionation, enzymatic methods, and peptide mapping, ref. 9-12) have been proposed. Although the cellular metabolism of glucagon has been much less well studied, use of methods similar to those employed for the study of insulin has provided evidence for both lysosomal (13) and extralysosomal (14-16) routes of glucagon metabolism by hepatocytes and other tissues.

Since the hepatic metabolism of glucagon represents a subject of considerable importance to an understanding of glucagon action and physiology, and since the hepatic insulin and glucagon receptor systems differ greatly in structure and in receptor-mediated function (17-20), we undertook to investigate in detail the mechanisms by which glucagon is metabolized by the hepatic parenchyma. By use of isolated canine hepatocytes and three specifically radiolabeled probes of the glucagon receptor [( $\left.{ }^{125} \mathrm{I}\right)$ iodoTyr ${ }^{10}$-glucagon, $\left({ }^{125} \mathrm{I}\right)$ iodo $\mathrm{Tyr}^{10,13}$-glucagon and $\left({ }^{125} \mathrm{I}\right)$ iodoTyr ${ }^{13}$-glucagon], we have already identified as a cellassociated intermediate of glucagon metabolism a peptide fragment, glucagon(4-29), that arises from removal of the $\mathrm{NH}_{2}$-terminal three residues of the hormone by limited proteolysis (16). This fragment is reminiscent of cell-associated fragments of insulin that have been demonstrated in related systems $(11,21)$ and is consistent with the participation of aminopeptidases in glucagon metabolism (22). Most important, the proteolytic modification resulting in the formation of glucagon(4-29) occurs in a region of the molecule that is known to confer both receptor binding affinity and biological activity to the hormone (23-25). Mechanisms for the further cellular handling of glucagon(4-29) have not been investigated, however, and could involve cellmediated degradation (perhaps by the lysosome), intracellular accumulation, or extrusion into the incubation medium. We report here the use of $\left({ }^{125} \mathrm{I}\right)$ iodoTyr ${ }^{10}$-glucagon and isolated hepatocytes on the one hand, and of glucagon radioimmunoassays and animal models on the other, to probe the formation and significance of glucagon(4-29) in vitro and in vivo.

\section{Methods}

Peptides and peptide radioiodination. Glucagon was obtained from ELANCO (a division of Eli Lilly and Co., Indianapolis, IN) and was subjected to radioiodination by use of peptide, $\mathrm{Na}^{125}$ I and chloramine $\mathrm{T}$ in essentially equimolar amounts. The mixture was then partially purified by ion-exchange chromatography on a column $(1 \times 1 \mathrm{~cm})$ of quarternary (QAE)-Sephadex A-25 to remove residual ${ }^{125} \mathrm{I}^{-}$, and the eluted peptides were applied directly to reverse-phase $\mathrm{C}-18$ columns (Altex $\mathrm{C}_{18}$ ultrasphere, ion-pairing, $5-\mu \mathrm{m}$ particle size, $0.46 \times 25 \mathrm{~cm}$ ) for further purification by isocratic high performance liquid chromatography. Details of the iodination procedure, the chromatographic system, the identifcation of labeled peptides, and the final purification of $\left({ }^{125} \mathrm{I}\right)$ iodo Tyr ${ }^{10}$. glucagon and $\left({ }^{125} \mathrm{I}\right)$ iodoTyr ${ }^{13}$-glucagon can be found elsewhere $(16,26)$. Radiolabeled peptide fragments (for use as molecular weight markers 
during gel filtration) were prepared as follows. ${ }^{125}$ I-labeled glucagon(112) was prepared by digesting intact $\left({ }^{125} \mathrm{I}\right)$ iodoTyr ${ }^{10}$-glucagon with tosylphenylalaninyl chloromethyl ketone-treated trypsin (Cooper Biomedical, Malvern, PA); the labeled dodecapeptide was purified by gel filtration on Bio-Gel P-2 as described (16). Glucagon(1-21) was prepared by digesting $1 \mathrm{mg}$ of the native hormone with $50 \mu \mathrm{g}$ of carboxypeptidase $A$ in $1.2 \mathrm{ml}$ of $0.15 \mathrm{M}$ Tris, $0.1 \mathrm{M} \mathrm{NaCl}$, and $0.025 \mathrm{M} \mathrm{CaCl}_{2}$ at pH 8.0 for $60 \mathrm{~min}$ at $37^{\circ} \mathrm{C}$; the mixture was purified on Bio-Gel P-6 run in $3 \mathrm{M}$ acetic acid. Eluted peptides were monitored by absorbance at $278 \mathrm{~nm}$. Peak fractions were pooled and lyophilized, and the composition of glucagon(1-21) was verified by amino acid analysis. The peptide $(5 \mu \mathrm{g})$ was iodinated using the same chloramine T-based procedure described for glucagon and the mixture was purified on a column (1 $\times 30 \mathrm{~cm}$ ) of QAE-Sephadex run in $80 \mathrm{mM}$ Tris buffer at $\mathrm{pH} 8.6$. ${ }^{125} \mathrm{I}-$ labeled glucagon(1-17) was prepared by digesting ${ }^{125}$ I-labeled glucagon(121) with $5 \mu \mathrm{g}$ of preactivated clostripain (Cooper Biomedical, a proteinase that cleaves $\mathrm{COOH}$-terminal to $\mathrm{Arg}$ ) in $0.4 \mathrm{ml}$ of $0.05 \mathrm{M}$ sodium phosphate containing $2 \mathrm{mM} \mathrm{CaCl}_{2}$ and $2.5 \mathrm{mM}$ dithiothreitol at $\mathrm{pH} 8.0$ for $4 \mathrm{~h}$ at $22^{\circ} \mathrm{C}$. Human $\left({ }^{125} \mathrm{I}\right)$ iodoTyr $\mathrm{r}^{\mathrm{A}}{ }^{14}$-insulin (purified by high performance liquid chromatography) was the gift of Dr. Bruce Frank of the Lilly Research Laboratories, Indianapolis, IN.

Cell and membrane isolation and incubation. Hepatocytes were isolated from canine or rat liver by collagenase digestion, as described elsewhere $(16,26)$; cells exhibited viabilities equal to or exceeding $98 \%$, as assessed by the exclusion of the dye trypan blue. Suspensions of isolated hepatocytes $\left(1 \mathrm{ml}, 2 \times 10^{6}\right.$ cells) were incubated in glass scintillation vials under an atmosphere of $95 \% \mathrm{O}_{2}$ and $5 \% \mathrm{CO}_{2}$, usually at $30^{\circ} \mathrm{C}$, in Krebs-Ringer bicarbonate buffer containing $\left({ }^{125} \mathrm{I}\right)$ iodoTyr ${ }^{10}$-glucagon $(\sim 20 \mathrm{fmol})$. Details of experimental procedures, incubation buffers and incubation periods are provided in figure legends and in ref. 16. At the close of each incubation for analysis of cell-associated peptide, suspensions were diluted with 8 to $10 \mathrm{vol}$ of ice-cold incubation medium, cells were pelleted at $200 \mathrm{~g}$ for $1 \mathrm{~min}$ at $4^{\circ} \mathrm{C}$, the supernatant fluid was removed by aspiration, acetic acid $(0.2 \mathrm{ml})$ was added to each pellet without delay, pellets were resuspended in the acetic acid, and the resulting mixture was counted for radioactivity. The tubes were then centrifuged, and the supernatant fluid removed and diluted with 4 vol of water before further analysis; $92-95 \%$ of cell-associated radioactivity was extracted by this procedure. At the close of each incubation for analysis of medium-associated peptides, the cell suspension was cooled to $4^{\circ} \mathrm{C}$ and centrifuged at $200 \mathrm{~g}$ without dilution, an aliquot of the ice-cold supernatant was added to one-fourth volume of acetic acid, and the acidified medium was stored at $-20^{\circ} \mathrm{C}$ pending further study. Hepatic plasma membranes were prepared from canine liver by application of standard methods (18, 27), and were incubated with ( $\left.{ }^{125} \mathrm{I}\right)$ iodo $\mathrm{Tyr}^{10}{ }^{-g l u c a g o n}$ in a buffer of 0.05 $M$ Tris containing $0.1 \mathrm{M} \mathrm{NaCl}, 0.01 \mathrm{M} \mathrm{MgCl}_{2}$, and $0.2 \%$ (wt/vol) bovine serum albumin at $\mathrm{pH} 7.4$ for $30 \mathrm{~min}$ at $30^{\circ} \mathrm{C}$, after which the membranes were diluted with 4 vol of ice cold Tris buffer and were pelleted by centrifugation at $2,000 \mathrm{~g}$ for $20 \mathrm{~min}$ at $4^{\circ} \mathrm{C}$. The final pellet was immediately dissolved in $0.2 \mathrm{ml}$ of glacial acetic acid and counted for radioactivity prior to further analysis.

Peptide analysis. Diluted acetic acid extracts of cell or membrane pellets or of acidified incubation medium were gel-filtered on columns $(2.5 \times 90 \mathrm{~cm})$ of Bio-Gel P-6 equilibrated with $3 \mathrm{M}$ acetic acid; the flow rate was about $15 \mathrm{ml} / \mathrm{h}$ and 4-ml fractions were collected and counted for radioactivity. In some cases, radioactive material appearing as a descending shoulder on the peak of intact ${ }^{125} \mathrm{I}$-labeled glucagon (material identified as a glucagon fragment from which the $\mathbf{N H}_{\mathbf{2}}$-terminal three residues of the hormone have been removed and which arises from the cell-mediated processing of glucagon, ref. 16) was $(a)$ pooled with 0.1 $\mathrm{mg}$ of glucagon as carrier and dried under vacuum, $(b)$ digested with tosylphenylalaninyl chloromethyl ketone-treated trypsin $(1 \mathrm{ml}$ of an 0.015 $\mathrm{mg} / \mathrm{ml}$ solution prepared in $0.2 \mathrm{M}$ Tris and $0.02 \mathrm{M} \mathrm{CaCl}_{2}$ brought to pH 7.8 with $\mathrm{HCl}, 60 \mathrm{~min}, 37^{\circ} \mathrm{C}$ ), and (c) subjected to gel filtration on columns $(2.5 \times 90 \mathrm{~cm})$ of Bio-Gel P-2 equilibrated with $3 \mathrm{M}$ acetic acid containing $5 \mu \mathrm{g} / \mathrm{ml}$ of bovine serum albumin. The 4-ml fractions were then counted for radioactivity to quantitate accurately the formation of glucagon(4-12), a fragment that arises from the tryptic cleavage of glu- cagon(4-29) and that is well separated from the glucagon(1-12) that arises from contaminating intact glucagon; further details of analysis and interpretation of this method of tryptic peptide mapping are described in ref. 16. Bio-Gel P-6 columns $(2.5 \times 85 \mathrm{~cm})$ used for the gel filtration of plasma extracted on $\mathrm{C}-18$ cartridges were eluted with $3 \mathrm{M}$ acetic acid containing $10 \mu \mathrm{g} / \mathrm{ml}$ of bovine serum albumin; $2.5-\mathrm{ml}$ fractions were collected, lyophilized, and subjected to radioimmunoassay.

Plasma extraction. Plasma (obtained from blood drawn into a solution containing $1.2 \mathrm{mg} / \mathrm{ml}$ of EDTA and 500 kallikrein inhibitor units per $\mathrm{ml}$ of aprotinin) was loaded without delay onto prewetted C-18 cartridges (Sep-Pak, Waters, Milford, MA) (25 ml of plasma/cartridge) at a rate of $15 \mathrm{ml} / \mathrm{h}$. The cartridge was then sequentially washed at a rate of $15 \mathrm{ml} /$ $\mathrm{h}$ with $5 \mathrm{ml}$ each of the following four solutions: $20 \%$ (vol/vol) acetonitrile prepared in water containing $1 \%(\mathrm{vol} / \mathrm{vol})$ trifluoroacetic acid, water containing $1 \%$ trifluoroacetic acid, $20 \%$ (vol/vol) methylene chloride prepared in acetonitrile, and undiluted acetonitrile. Peptide hormones were then eluted in $4 \mathrm{ml}$ of $45 \%$ acetonitrile (vol/vol) prepared in water containing $1 \%$ trifluoroacetic acid. Absorbance measurements at 278 $\mathrm{nm}$ revealed that this eluant contained about $1.5 \mathrm{mg}$ of protein for each $25 \mathrm{ml}$ of plasma extracted; the solutions were concentrated and subjected to gel filtration. Control studies showed that the recoveries of ${ }^{125}$ I-labeled glucagon and ${ }^{125}$ I-labeled glucagon(4-29) (the latter obtained by gel filtration after metabolism of iodoglucagon by isolated hepatocytes, see Fig. 1), each well-mixed with $25 \mathrm{ml}$ of outdated human plasma and extracted on C-18 cartridges using the protocol described, were $87 \%$ and $86 \%$, respectively. Additional studies involving the addition of ${ }^{125}$ I-labeled glucagon or unlabeled glucagon to freshly drawn blood, concentration of plasma peptides on $\mathrm{C}-18$ cartridges, and analysis by gel filtration showed that $<7 \%$ of the added hormone was converted to material resembling glucagon(4-29) during the processing of samples in the laboratory.

Radioimmunoassays. The buffer contained $0.2 \mathrm{M}$ glycine, $0.25 \%$ (wt/vol) normal human serum albumin, $1 \%$ (vol/vol) normal lamb serum, $1.3 \mathrm{mM} \mathrm{Na}_{2}$ EDTA, $3 \mathrm{mM} \mathrm{NaN}_{3}$, and 100 kallikrein inhibitor units $/ \mathrm{ml}$ aprotinin, all at $\mathrm{pH}$ 8.8. Radioimmunoassays using glucagon antiserum G-15 (rabbit, 11/2/77 bleed) at a final dilution of 1:500,000 employed nonequilibrium conditions that involved incubation of antibody with sample for $72 \mathrm{~h}$ at $4^{\circ} \mathrm{C}$, followed by addition of labeled glucagon and further incubation for $24 \mathrm{~h}$ at $4^{\circ} \mathrm{C}$, before separation of antibody-bound ligand by use of goat anti-rabbit IgG. Nonspecific binding in the assay was about $6 \%$, and the assay sensitivity, as assessed by the least amount of glucagon producing significant displacement of ${ }^{125} \mathrm{I}$-glucagon from antibody, was $2.6 \mathrm{pg} /$ tube. Radioimmunoassays using antiserum K-4023 (Novo Research Institute, Copenhagen, Denmark) at a final dilution of 1:24,000 employed equilibrium incubation of antibody with samples and labeled glucagon for $24 \mathrm{~h}$ at $4^{\circ} \mathrm{C}$ followed by separation of antibodybound ligand by precipitation with polyethylene glycol. Nonspecific binding was $7 \%$ and assay sensitivity was $\sim 20 \mathrm{pg} /$ tube. Representative standard curves from radioimmunoassays using these antisera are shown in Fig. 8.

Human subjects and animal studies. Human subjects underwent overnight fasts, after which whole venous blood was drawn. The resulting plasma contained glucagon immunoreactivity in the range of 102 to 137 $\mathrm{pg} / \mathrm{ml}$ for the three normal subjects and $360 \mathrm{pg} / \mathrm{ml}$ for pooled plasma from subjects with chronic renal failure requiring dialysis. Peripheral venous infusion studies used an infusion catheter placed in the femoral vein, and a sampling catheter in the femoral artery, of an anesthetized male mongrel dog. A primed infusion of somatostatin (a $90-\mu \mathrm{g}$ bolus injection followed by a constant infusion of $600 \mathrm{ng} / \mathrm{kg}$ per min) was begun $100 \mathrm{~min}$ before initiation of the primed glucagon infusion (a 2.3$\mu \mathrm{g}$ bolus injection followed by a constant infusion of $7.5 \mathrm{ng} / \mathrm{kg}$ per $\mathrm{min}$ ). $30 \mathrm{~min}$ after the glucagon infusion had begun, $50 \mathrm{ml}$ of blood was drawn from the sampling catheter. Radioimmunoassay of plasma samples taken at 10-min intervals starting $30 \mathrm{~min}$ before the glucagon infusion confirmed both that the somatostatin had suppressed endogenous hormone secretion, and that plasma glucagon levels had reached steady state $(\sim 550$ $\mathrm{pg} / \mathrm{ml}$ ) well before the $50-\mathrm{ml}$ sample was drawn. Studies investigating transhepatic gradients of circulating glucagon metabolites during endogenous hormone secretion in the anesthetized dog employed sampling 
catheters placed in the hepatic vein $(1,2)$ and in the pancreaticoduodenal vein (1) of the same dog used in the peripheral infusion study above, although care was taken to give the dog one week to recover between the two experiments. Whole blood $(50 \mathrm{ml})$ was separately drawn from each vein in $2.5 \mathrm{ml}$ of EDTA/aprotinin solutions, and plasma was separately extracted by $\mathrm{C}-18$ cartridges, gel filtered, and the fractions subjected to radioimmunoassay, all as described above; direct radioimmunoassay of plasma showed that pancreaticoduodenal and hepatic vein levels of immunoreactive glucagon were 459 and $310 \mathrm{pg} / \mathrm{ml}$, respectively. Studies investigating transrenal gradients employed blood sampling from the renal artery and renal vein in a second animal and followed a similar course.

\section{Results}

Studies involving cell incubation. Initial studies on the cellular metabolism of glucagon examined the formation of $\left({ }^{125} \mathrm{I}\right)$ iodoTyr ${ }^{10}$-glucagon-derived degradation products arising from the incubation of the ${ }^{125} \mathrm{I}$-labeled hormone with isolated hepatocytes or hepatic plasma membranes. Fig. $1 a-c$ show gel filtration profiles of cell- or membrane-associated, radiolabeled material resulting from hormone incubation with canine hepatocytes, rat hepatocytes, and canine hepatic plasma membranes, respectively. As illustrated in Fig. $1 a$, while the majority of cell-associated radioactivity is identified as intact hormone, a cell-associated glucagon metabolite (determined to be ${ }^{125} \mathrm{I}$-labeled glucagon(4-29); i.e., glucagon lacking its three $\mathrm{NH}_{2}$-terminal residues, Ref. 16) appears as a descending shoulder on the peak of ${ }^{125}$ I-labeled glucagon. Whereas identical profiles were obtained from incubations involving canine and rat hepatocytes (compare Fig. $1 a$ and $b$ ), Fig. $1 c$ shows that incubation of canine hepatic plasma membranes with ${ }^{125}$ I-labeled glucagon failed to yield an equivalent, membrane-associated fragment of the hormone.

An analysis of ${ }^{125}$ I-labeled products $(a)$ resulting from the incubation of canine hepatocytes with ${ }^{125}$ I-labeled glucagon and (b) appearing in the extracellular incubation medium, is presented in Fig. 2. Fig. $2 a$ shows that, in addition to the major peak of intact hormone and the shoulder on the descending limb of this peak, cell incubation medium contains at least two readily observed lower molecular weight, ${ }^{125}$ I-labeled compo- nents. Importantly, the pattern of radiolabeled degradation products remained unchanged when cells were incubated at $37^{\circ} \mathrm{C}$ rather than $30^{\circ} \mathrm{C}$ (Fig. $2 \mathrm{~b}$ ) or when $\left({ }^{125} \mathrm{I}\right)$ iodo $\mathrm{Tyr}^{13}$-glucagon, rather than $\left({ }^{125} \mathrm{I}\right)$ iodoTyr ${ }^{10}$-glucagon, was used as the radiolabeled probe (Fig. $2 c$ ). The use of ${ }^{125}$-labeled molecular weight markers in Fig. $2 a$ suggests that the molecular weights of the glucagon metabolites identified in incubation medium, but not in association with cells, are $\sim 2,000$ and 1,400 .

As an approach to determining the structures of the glucagon metabolites that appear in cell incubation medium, and specifically to determine whether they had been shortened from the $\mathrm{NH}_{2}$-terminus of the intact hormone, selected fractions from the profile of Fig. $2 a$ were pooled and the resulting material was subjected sequentially to digestion by trypsin and gel filtration on Bio-Gel P-2. Subsequent to digestion by trypsin, pool 1 of Fig. $2 a$ (material representing intact hormone) consisted of a single major radiolabeled peptide fragment (peak I, Fig. $3 a$ ) which gel filtered at the position of glucagon(1-12). In contrast, pool 2 (material present in the descending shoulder on the peak of intact hormone) was converted to two well defined peptide fragments (peaks I and II, Fig. $3 b$ ). The first corresponds to ${ }^{125} \mathrm{I}-$ labeled glucagon(1-12) (a peptide generated from digestion of intact hormone present in the broad pool); the second corresponds to ${ }^{125}$ I-labeled glucagon(4-12) [a peptide generated from digestion of glucagon(4-29)]. Further, automated radiosequence analysis of material in pool 2 identified the release of ${ }^{125}$ I)iodotyrosine after the seventh cycle of Edman degradation, a result confirming that the glucagon-derived peptide that elutes as a descending shoulder on the peak of intact hormone during gel filtration represents a metabolite from which the $\mathrm{NH}_{2}$-terminal three residues of the hormone had been removed by limited proteolysis (data not shown). Fig. $3 c$ and $d$ show that the lower molecular weight, glucagon-derived peptides identified in cell incubation medium, in contrast to glucagon(4-29), contain intact $\mathrm{NH}_{2}$-terminal regions: in both cases, trypsin digestion resulted in the formation of the fragment glucagon(1-12).

Since results described above, in combination with previous findings (16), indicate the requisite participation of isolated hepatocytes in the formation and release of glucagon(4-29), we examined the rates of appearance of both cell- and medium-
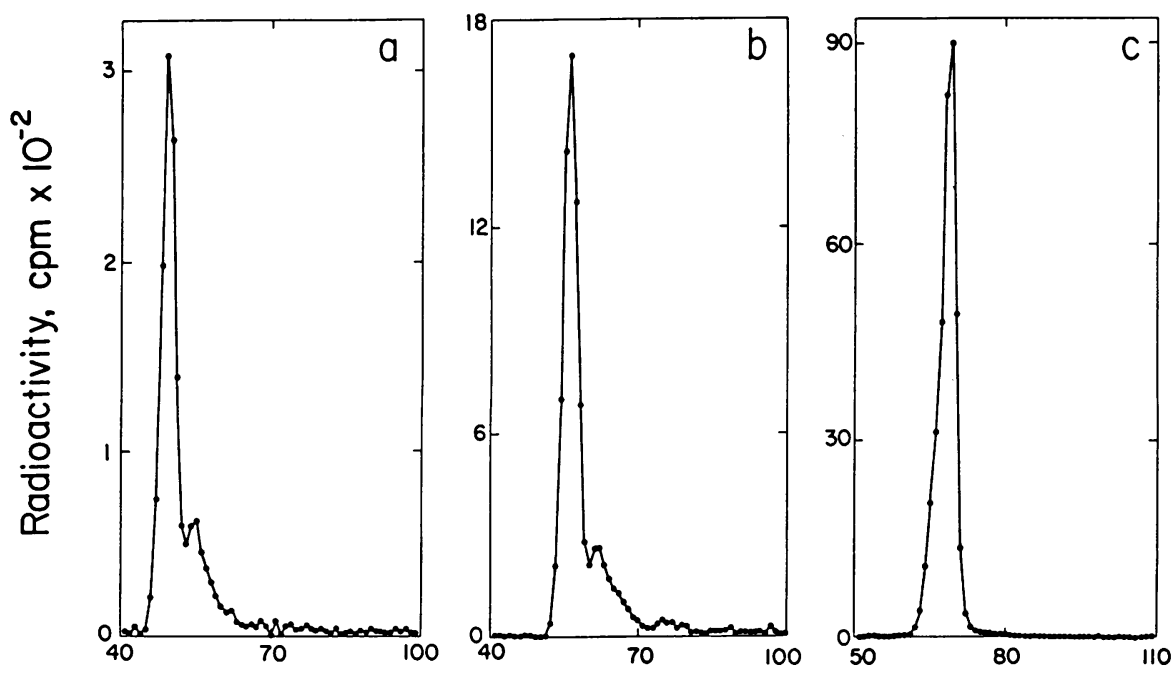

Fraction Number
Figure 1. Gel filtration on Bio-Gel P-6 of cell- and membrane-associated peptides arising from the incubation of hepatocytes or hepatic plasma membranes with ${ }^{125} \mathrm{I}$-labeled glucagon. Incubations occurred during $30 \mathrm{~min}$ at $30^{\circ} \mathrm{C} .(a-c)$ show the radioactivity in each 4-ml fraction plotted against fraction number for ${ }^{125}$ I-labeled glucagon incubated with isolated canine hepatocytes, isolated rat hepatocytes, and isolated canine hepatic plasma membranes, respectively. 


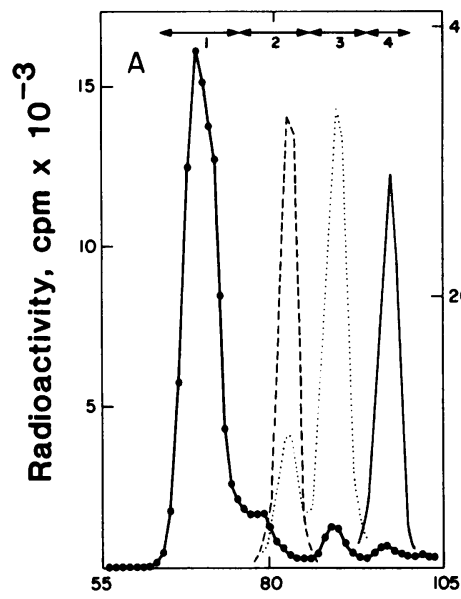

Fraction Number

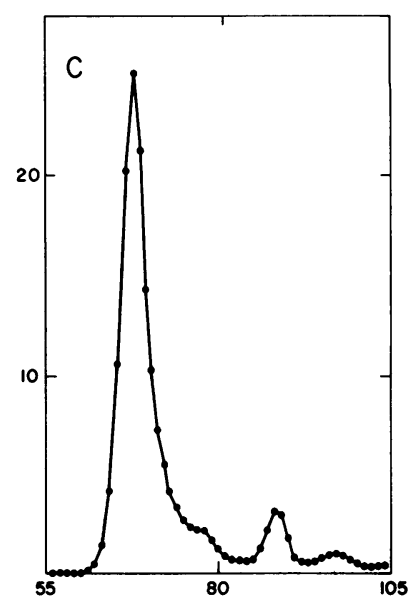

105
Figure 2. Gel filtration on Bio-Gel P-6 of cell medium derived from the incubation of canine hepatocytes with ${ }^{125} \mathrm{I}$-labeled glucagon. The solid lines of $(a-c)$ show radioactivity in each 4-ml fraction plotted against fraction number for hepatocytes incubated, respectively, with $\left.{ }^{(25} \mathrm{I}\right)$ iodoTyr ${ }^{10}$-glucagon at $30^{\circ} \mathrm{C}$, with $\left({ }^{125} \mathrm{I}\right)$ iodoTyr ${ }^{10}$-glucagon at $37^{\circ} \mathrm{C}$, and with $\left({ }^{125} \mathrm{I}\right)$ iodo Tyr ${ }^{13}$-glucagon at $30^{\circ} \mathrm{C}$; the incubation period was $30 \mathrm{~min}$ in each case. Horizontal arrows in $(a)$ indicate fractions that were pooled for further analysis. In addition, panel $a$ shows the elution positions of ${ }^{125}$ I-labeled glucagon(121) (dashed line), glucagon(1-17)

(dotted line) and glucagon(1-12) (solid line), compounds that were used as column markers; for clarity of presentation, data points have been omitted.

associated glucagon(4-29) during the incubation of canine hepatocytes with $\left({ }^{125} \mathrm{I}\right)$ iodo Tyr $^{10}$-glucagon by use of tryptic peptide mapping as applied in Fig. 3. Profiles showing patterns of radioactivity obtained after Bio-Gel P-2 gel filtration are shown in Fig. 4. Whereas the data of Fig. $4 a$ and $b$ demonstrate a small decrease in the amount of cell-associated glucagon(4-29) attending the extention of the incubation period from 30 to 60 min, the data of Fig. $4 c, d$, and $e$ demonstrate a progressive increase in the relative amount of medium-associated glucagon(4-29) as the incubation period is extended from 15 to 75 min. Since Fig. 4 defines the appearance of glucagon(4-29) as a percent of total cell- or medium-associated radioactivity, it should also be noted that the amount of glucagon-derived material present in incubation medium exceeds that associated with cells by 8- to 10-fold; thus, the absolute amount of glucagon(4-29) accumulating in the medium is greater than that of the cellbound material at all incubation periods examined.

To see whether any of a variety of lysosomotropic or other agents would affect the formation of cell- or medium-associated glucagon(4-29), isolated hepatocytes were incubated with chloroquine, dansyl-cadaverine, procaine, leucine methyl ester or bacitracin, and cell and medium radioactivity was analyzed as before by gel filtration. Data presented in Table I demonstrate that none of these drugs altered the appearance of glucagon(429 ) to a significant degree under our conditions (whether considering the cell- or medium-associated hormone fragment), and that only bacitracin inhibited the conversion of glucagon to lower molecular weight peptides that include those resulting from proteolytic processing in the $\mathrm{COOH}$-terminal region of the hormone. The potential effects of chloroquine on the processing of receptorbound glucagon were further examined in comparison with the processing of receptor-bound insulin. As shown by the binding time courses of Fig. 5, chloroquine had no effect on the association of $\left({ }^{125} \mathrm{I}\right)$ iodo $\mathrm{Tyr}^{10}$-glucagon with hepatocytes, although it increased markedly the association of $\left({ }^{125} \mathrm{I}\right)$ iodoTyr ${ }^{\mathrm{A} 14}$-insulin with hepatocytes incubated in parallel.

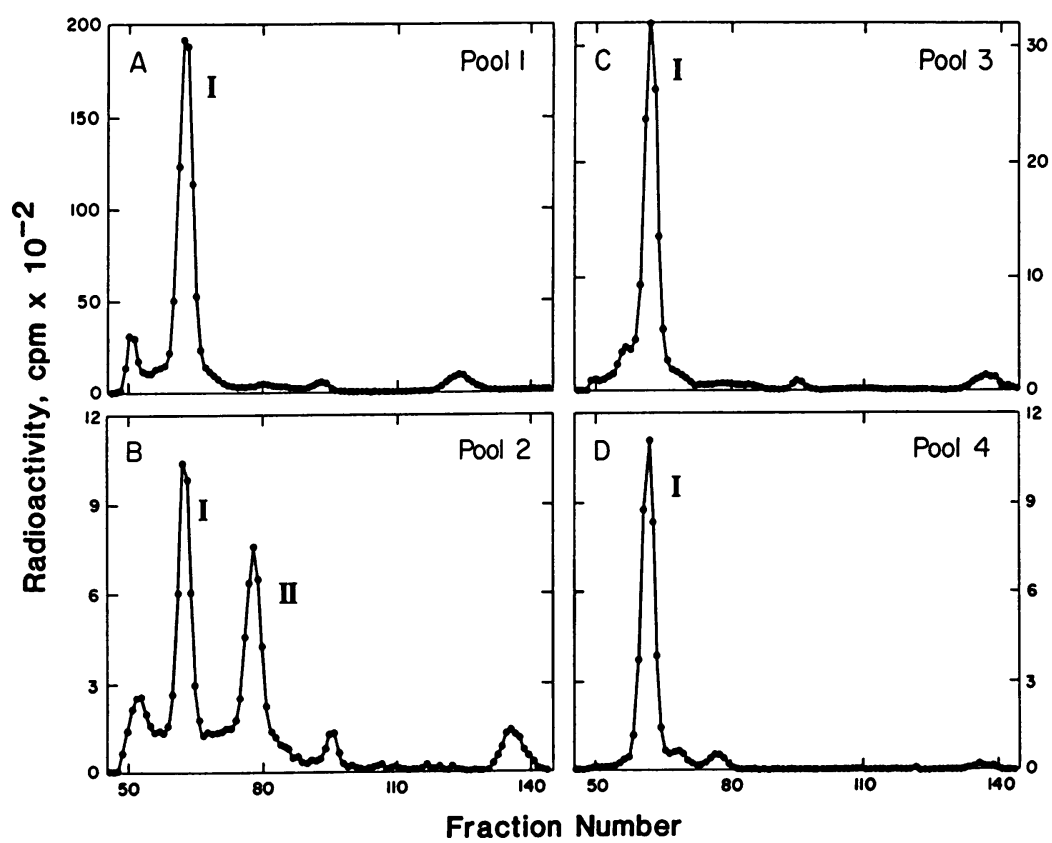

Figure 3. Gel filtration on Bio-Gel P-2 of trypsin-digested pooled fractions obtained from the experiment shown in Fig. $2 a$. Radioactivity present in each 4-ml fraction is plotted against fraction number for the four pools identified in Fig. $2 a$. $(a-d)$ represent material from pools $1,2,3$, and 4 , respectively. The peak labeled $I$ identifies glucagon(1-12) whereas that labeled $I I$ identifies glucagon(4-12). The highest molecular weight peaks correspond to small amounts of undigested radiolabeled glucagon. 


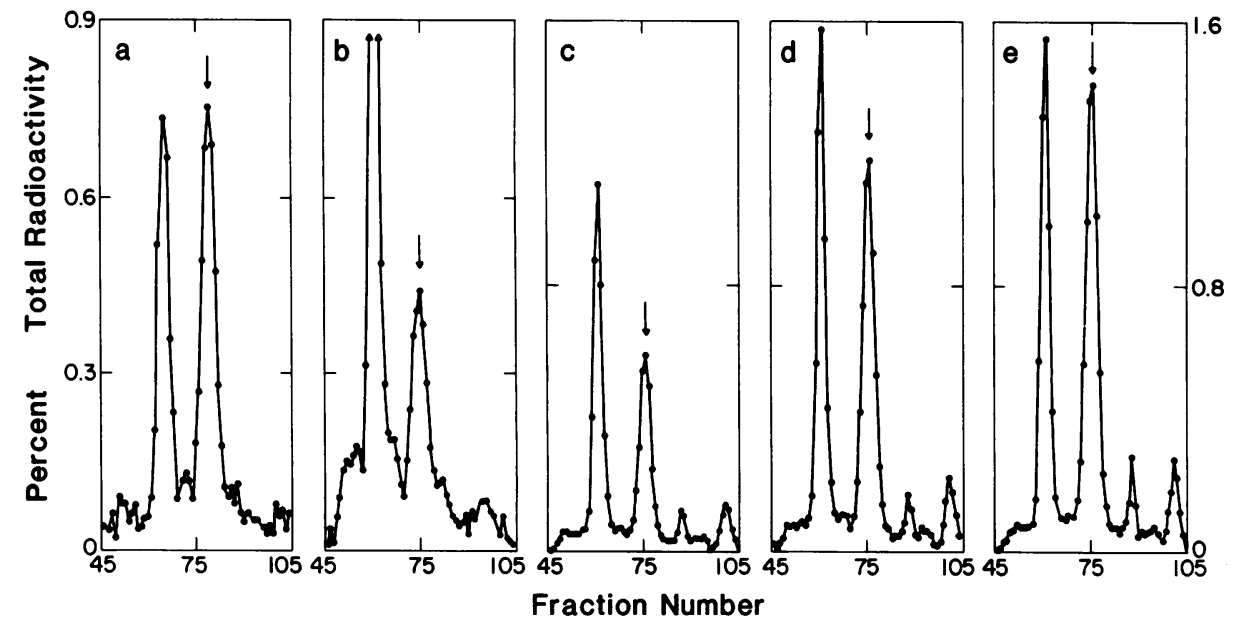

Figure 4. Gel filtration on Bio-Gel P-2 of trypsin-digested peptides present in the equivalent of pool 2 of Fig. $2 a$ arising from a time course of incubation of canine hepatocytes with ${ }^{125}$ I-labeled glucagon. The experiment was designed to probe both the formation of glucagon(429 ) in association with isolated hepatocytes and the appearance of the glucagon metabolite in cell incubation medium; all incubations occurred at $30^{\circ} \mathrm{C}$. Radioactivity in the 4-ml fractions is plotted against fraction number for each circumstance. ( $a$ and $b$ ) Cell-associated radioactivity after incubation of hepatocytes with ${ }^{125} \mathrm{I}$-labeled glucagon for 30 and $60 \mathrm{~min}$, respectively. (c, $d$, and $e$ ) Radioactivity occurring in incubation

medium after incubation of hepatocytes with ${ }^{125} \mathrm{I}$-labeled glucagon for 15,30 , and $75 \mathrm{~min}$, respectively. The vertical arrow in each panel identifies the position taken by ${ }^{125}$ I-labeled glucagon(4-12). It should be noted that fractions from the P-6 column were pooled broadly and contained intact radiolabeled hormone; the amount of glucagon(1-12) (material eluting at fractions $60-65$ and resulting from contaminating intact ${ }^{125}$ I-labeled glucagon) thus varies considerably among the gel filtration profiles shown.

Studies involving plasma radioimmunoassay. Since isolated hepatocytes participate in the formation of glucagon(4-29) and release the hormone fragment into the medium, we reasoned that the metabolism of glucagon in vivo might well result in the appearance of glucagon(4-29) in plasma, a fluid that in many ways represents the physiological equivalent of cell incubation medium. By use of C-18 cartridges to concentrate plasma immunoreactive glucagon and, gel filtration to separate potentially heterogeneous forms, we analyzed plasma immunoreactive glu-

Table I. Gel Filtration Analysis on Bio-Gel P-6 of the Effects of Various Pharmacological Agents on the Formation of Glucagon Metabolites Arising from the Incubation of Canine Hepatocytes with ${ }^{125}$ I-labeled Glucagon for $30 \mathrm{~min}$ at $30^{\circ} \mathrm{C}$

\begin{tabular}{|c|c|c|c|c|c|}
\hline \multirow[b]{2}{*}{ Agent, concentration } & \multicolumn{2}{|c|}{$\begin{array}{l}\text { Cell associated } \\
\text { material }\end{array}$} & \multicolumn{3}{|c|}{ Medium associated material } \\
\hline & Intact ${ }^{*}$ & $4-29^{*}$ & Intact* & $4-29^{\ddagger}$ & Low mol wt \\
\hline & \multicolumn{5}{|c|}{$\%$ applied radioactivity } \\
\hline (none) & 94 & 6 & 57 & 9 & 30 \\
\hline \multicolumn{6}{|l|}{ Chloroquine } \\
\hline (1 mM) & 92 & 8 & 58 & 9 & 29 \\
\hline \multicolumn{6}{|l|}{ Dansyl-cadaverine } \\
\hline$(0.4 \mathrm{mM})$ & 93 & 7 & 56 & 9 & 31 \\
\hline Procaine (2 mM) & 94 & 6 & 57 & 8 & 32 \\
\hline \multicolumn{6}{|l|}{ Leucine methyl ester } \\
\hline$(2 \mathrm{mM})$ & 94 & 6 & 49 & 10 & 37 \\
\hline Bacitracin $(0.7 \mathrm{mM})$ & 94 & 6 & 76 & 8 & 11 \\
\hline
\end{tabular}

* Material appearing at the position taken by intact hormone during gel filtration.

${ }^{\ddagger}$ Material appearing as a descending shoulder on the peak of intact hormone and at the position taken by glucagon(4-29) during gel filtration.

${ }^{\S}$ The sum of material appearing after glucagon(4-29) during gel filtration. This material represents lower molecular weight peptides shortened from the glucagon $\mathrm{COOH}$-terminus, as well as $\left({ }^{125} \mathrm{I}\right)$ iodoTyr and ${ }^{125} \mathrm{I}^{-}$. cagon from three fasting normal human subjects. As shown in Fig. 6, the majority of immunoreactive glucagon was eluted at the position taken by intact hormone in each case. Fig. 6 further demonstrates in each case the appearance of a glucagon immunoreactive peptide (amounting to $\sim 25 \%$ of the total) that occurs as a descending shoulder on the peak of native glucagon. The lower apparent molecular size of this peptide, its elution at the position taken by ${ }^{125}$ I-labeled glucagon(4-29), and its immunoreactivity in an assay requiring an intact glucagon $\mathrm{COOH}$ terminus, all suggest that the material is the physiological equivalent of the cell- and medium-associated glucagon fragment identified earlier during hepatocyte incubations. The earliest eluting immunoreactive glucagon appearing in each panel of Fig. 6 elutes from the column just beyond the void volume and most likely represents the $\mathrm{NH}_{2}$-terminally extended form of the hormone (a proglucagon processing intermediate) that is readily observed in unconcentrated plasma only in individuals with renal failure or with glucagonoma $(28,29)$.

To ensure that the immunoreactive, glucagon-related peptide identified as glucagon(4-29) in Fig. 6 did not represent the low molecular weight interfering substance commonly detected in unconcentrated plasma by radioimmunoassays directed towards the glucagon $\mathrm{COOH}$-terminus $(30,31)$, we applied our radioimmunoassay to the profile obtained from the gel filtration of whole plasma on Bio-Gel P-30 in neutral buffer. Fig. $7 a$ shows that, under these conditions, glucagon and glucagon(4-29) are poorly separated. More important, Fig. $7 b$ clearly demonstrates that the commonly observed, low molecular weight substance (whether or not it is a fragment of glucagon) appears near the salt volume of the column rather than at the position taken by glucagon(4-29).

Additional studies on plasma glucagon(4-29) concerned the determination of the specificities of our radioimmunoassays and the evaluation of plasma derived from patients in chronic renal failure. Fig. $8 a$ compares representative radioimmunometric standard curves obtained by use of antisera G-15 and K-4023 and the relative affinities of the two antibodies for the ligands glucagon, glucagon(2-29), and glucagon(1-27). While both antisera interact as well with glucagon(2-29) as they do with the 


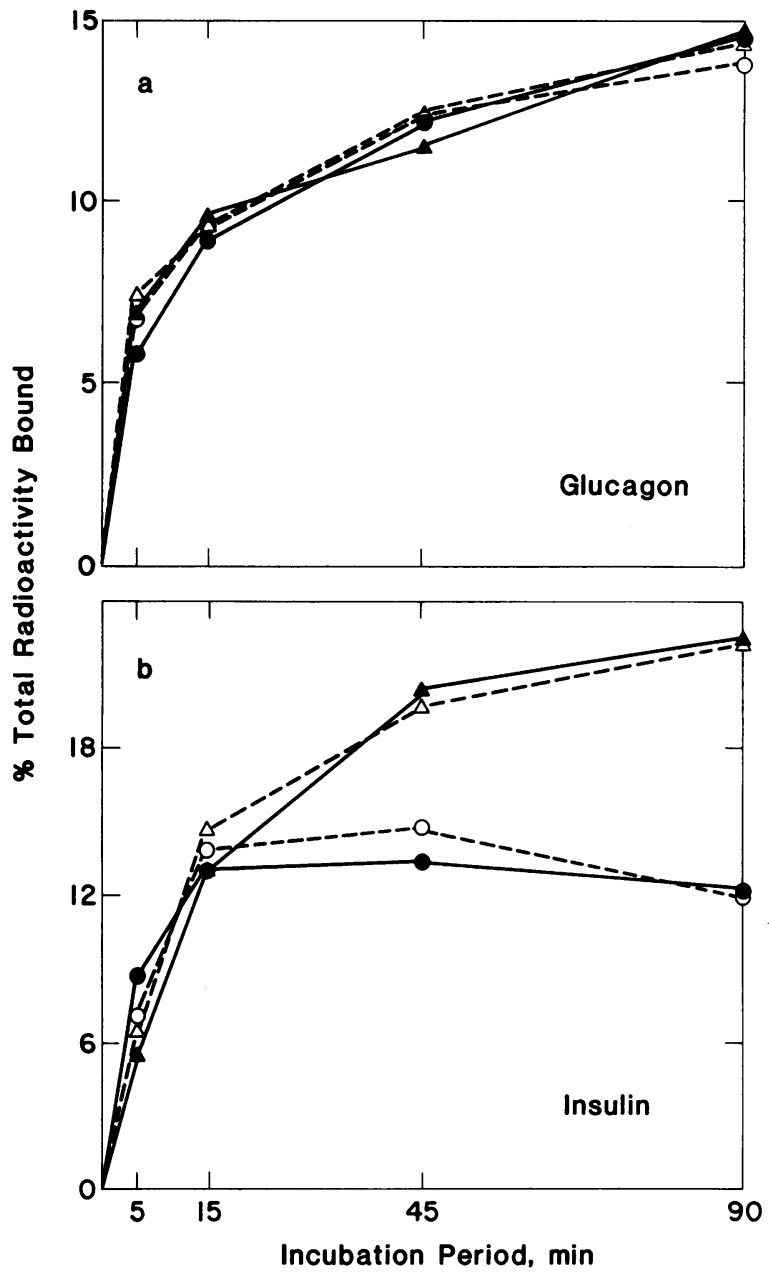

Figure 5. Time course is of binding of ${ }^{125}$ I-labeled glucagon and ${ }^{125}$ I-labeled insulin to isolated canine hepatocytes incubated in the presence or absence of chloroquine $(75 \mu \mathrm{M})$ and in the presence or absence of amino acids in the incubation medium. All incubations occurred at $30^{\circ} \mathrm{C}$. (a) cell-associated radioactivity resulting from incubation of hepatocytes with ${ }^{125} \mathrm{I}$-labeled glucagon in the absence (circles) or presence (triangles) of chloroquine. (b) cell-associated radioactivity resulting from incubation hepatocytes with ${ }^{125}$ I-labeled insulin in the absence (circles) or presence (triangles) of chloroquine. For both panels, closed symbols connected by solid lines denote incubations occurring in the presence of amino acids, while open symbols connected by dashed lines denote incubations occurring in the absence of amino acids.

intact hormone, the two show markedly different relative affinities for glucagon(1-27): antiserum K-4023 exhibits an affinity for glucagon(1-27) as much as half that for glucagon, whereas antiserum G-15 exhibits an affinity for the COOH-terminally modified peptide 50 -fold lower than that for native hormone. Thus, antiserum G-15 is directed specifically towards the $\mathrm{COOH}$ terminus of glucagon whereas antiserum $\mathrm{K}-4023$ is less sensitive to $\mathrm{COOH}$-terminal modification of the hormone. Fig. $8 b$ shows results obtained from applying each antiserum to the radioimmunoassay of fractions arising from the gel filtration of pooled chronic renal failure plasma. As expected, antiserum K-4023 is much more sensitive than antiserum G-15 to the detection of large, $\mathrm{COOH}$-terminally extended forms of glucagon (including glicentin) that appear near the void volume of the column. More important, both antisera detect glucagon and immunoreactive material eluting at the position of glucagon(4-29) equivalently. These results indicate that the material eluting at the position of glucagon(4-29) contains an intact glucagon $\mathrm{COOH}$-terminus and must have undergone processing exclusively at the $\mathrm{NH}_{2}$ terminus of the hormone. Fig. $8 b$ further shows that, despite higher than normal levels of circulating glucagon in plasma from patients with chronic renal failure, the glucagon metabolite glucagon(4-29) represents $\sim 25 \%$ of total pancreatic glucagon immunoreactivity, a fraction identical to that observed in normal individuals.

Finally, to confirm the significance of glucagon(4-29) in normal physiology, we examined the formation of the glucagon fragment in dogs. Fig. $9 a$ shows that glucagon(4-29) is present, but occurs in low relative amounts, in the peripheral plasma of an animal in which the constant, peripheral infusion of glucagon has raised the circulating hormone concentration to mildly supraphysiological values. Moreover, the gel filtration profiles of Fig. $9 b$ and $c$ (profiles reflecting the analysis of immunoreactive glucagon in plasma simultaneously sampled from the pancreaticoduodenal and hepatic veins of a single animal under laparotomy) identify the greater amount of glucagon(4-29) appearing in the posthepatic circulation relative to the appearance of the peptide in prehepatic plasma, and thus the hepatic generation of the immunoreactive peptide. In contrast, Fig. $9 d$ and $e$ demonstrate the absence of a differential gradient of glucagon and glucagon(4-29) across the canine kidney.

\section{Discussion}

Although it is a matter of some debate whether peptide hormone metabolism plays a role in the mechanism of hormone action (32-34), it is at least clear that hormone metabolism by target tissues is a function, in large part, of ligand interaction with plasma membrane receptors and that it occurs in parallel with processes by which hormone-receptor interactions regulate cellular events $(3-6,16)$. By use of isolated hepatocytes, we have demonstrated that $(a)$ a major peptide product of glucagon metabolism is glucagon(4-29), (b) the hormone fragment, rather than being stored or further degraded, is released into the cell incubation medium, and $(c)$ the fragment arises from cell-mediated processes that require components in addition to highly purified plasma membranes per se. Since modifications at the $\mathrm{NH}_{2}$-terminus of glucagon, including removal of residue $\mathrm{His}^{1}$, are known to decrease markedly the receptor binding affinity and biological activity of the hormone (23-25, 35-37), the cellmediated cleavage of glucagon at the $\mathrm{Gln}^{3}$-Gly ${ }^{4}$ peptide bond would provide an effective mechanism for terminating the hormone signal. Moreover, the decrease in receptor binding affinity attending formation of glucagon(4-29) would permit the dissociation of the hormone fragment from receptor and would thus account for its continuous release into the extracellular space. Although the participating endoproteinase has yet to be identified, it is of interest that an aminotripeptidase recently isolated from rat liver (38) would serve well in this regard, and that glucagon analogues with alterations in the $\mathrm{NH}_{2}$-terminal region of the hormone fail to be converted to fragments equivalent to glucagon(4-29) during incubation with canine hepatocytes (39).

Findings showing that the fragment glucagon(4-29) tends not to accumulate on or within incubated hepatocytes, is released into the extracellular space, and is unaffected by lysosomotropic 


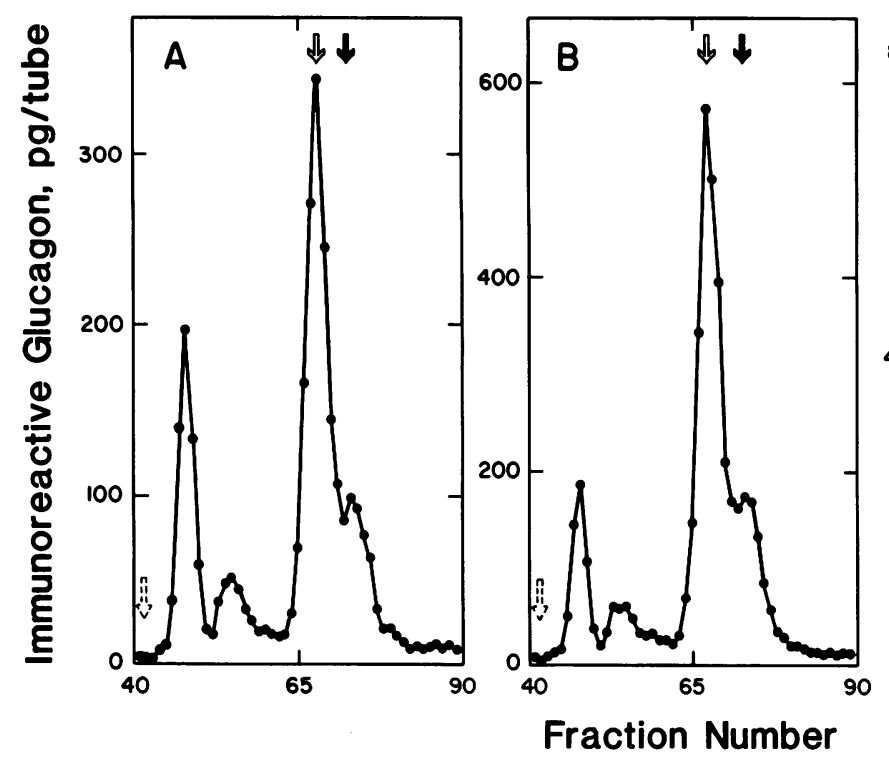

agents all suggest that the processing of the receptor-bound hormone occurs on a superficial aspect of the cell. Notwithstanding the facts that $(a)$ receptor-bound insulin may well be degraded by both lysosomal and nonlysosomal mechanisms (6-12) and (b) radioactivity derived from both ${ }^{125} \mathrm{I}$-labeled insulin and ${ }^{125} \mathrm{I}$ labeled glucagon has been identified in hepatocyte lysosomes by

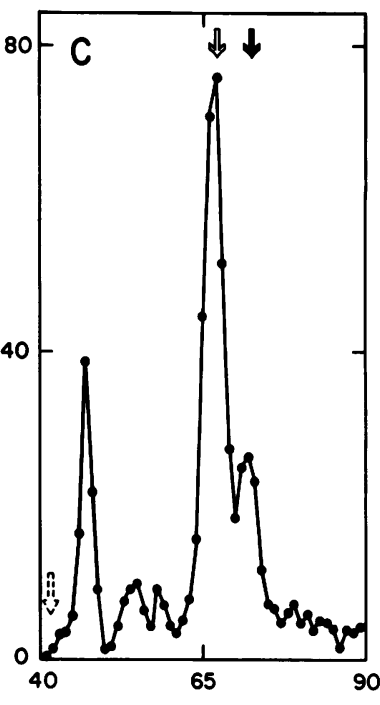

electron microscopic autoradiography $(7,8)$, our data suggest that quantitative aspects of processes resulting in the hepatic metabolism of the two hormones differ considerably. The relatively greater contribution in the case of glucagon of a mechanism possibly related to retroendocytosis (which occurs on the superficial aspect of hepatocytes and adipocytes and which di-
Figure 6. Gel filtration on Bio-Gel P-6 of immunoreactive glucagon extracted from human plasma by adsorption to C-18 cartridges. Immunoreactivity in each fraction is plotted against fraction number. $(a, b$, and $c$ ) Gel filtration profiles representing immunoreactive plasma glucagon derived from three different subjects as assayed by use of antiserum G-15. In all panels, the dashed arrow shows the void volume of the column, as determined by the elution of bovine serum albumin, and open and solid arrows show the elution positions of ${ }^{125} \mathrm{I}$-labeled glucagon and glucagon(4-29), respectively.
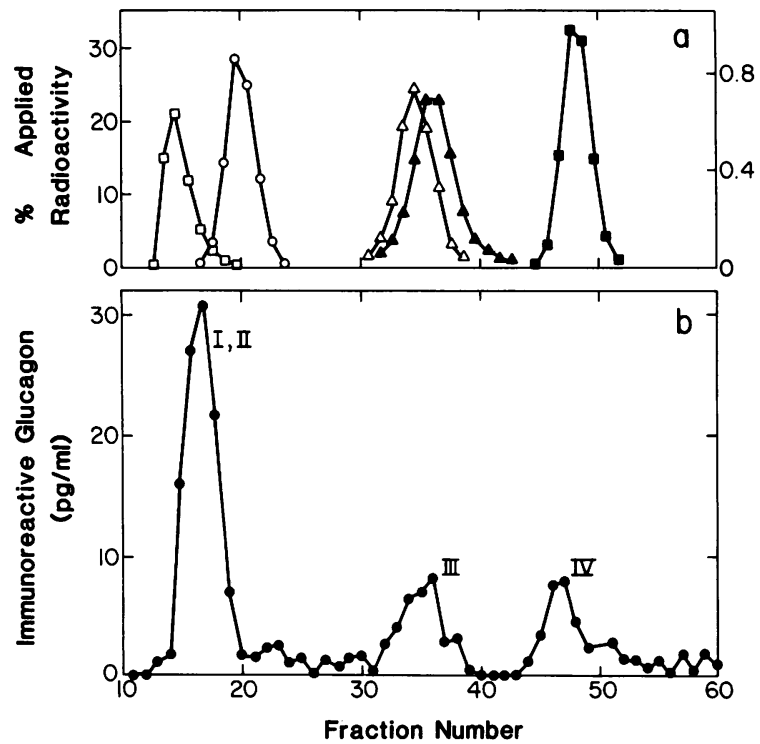

Figure 7. Gel filtration on Bio-Gel P-30 of unconcentrated human plasma. The column $(1.1 \times 50 \mathrm{~cm})$ was eluted with the $0.1 \mathrm{M}$ glycine buffer (pH 8.8) used in the G-15 radioimmunoassay (described in Methods). (a) Standards used to calibrate the column: open square, blue dextran; open circle, ${ }^{125}$ I-labeled human proinsulin; open triangle, ${ }^{125}$ I-labeled glucagon; closed triangle, ${ }^{125}$ I-labeled glucagon(4-29); closed square, $\mathrm{Na}^{125} \mathrm{I}$. The right hand ordinate applies to the standard of blue dextran only. (b) Plasma ( $1.5 \mathrm{ml}, 149 \mathrm{pg} / \mathrm{ml}$ of immunoreactive glucagon) obtained from a normal fasting subject. Fractions were subjected to radioimmunoassay using antiserum G-15. Three peaks of immunoreactivity were observed and are numbered by convention from the literature (30); the recovery of immunoreactive material applied to the column was $86 \%$.
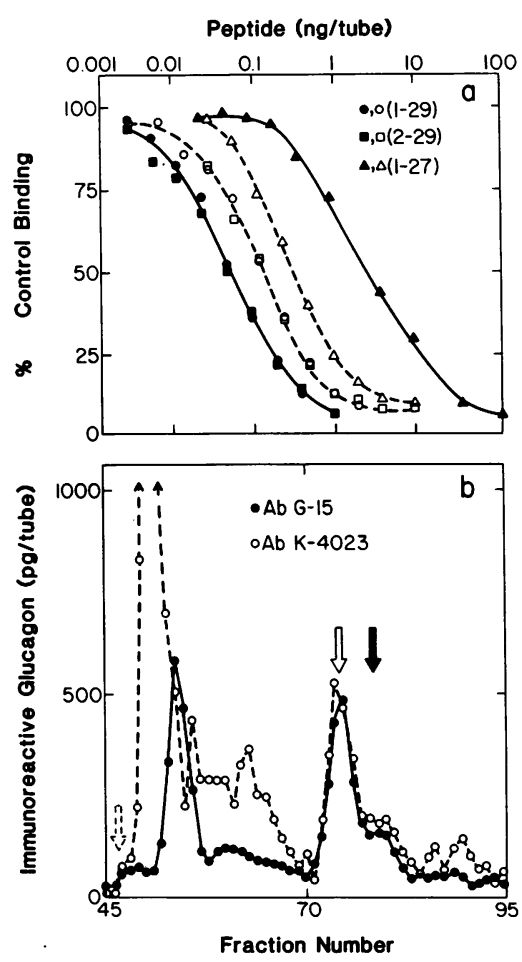
half and lyophilized, and the residue was dissolved in the appropriate radioimmunoassay buffer for assay by antiserum G-15 (closed circles) or antiserum K-4023 (open circles). Immunoreactive glucagon values have been adjusted to reflect material present in the original $2.5-\mathrm{ml}$ fractions. The dashed arrow shows the void volume of the column (as determined from the elution of bovine serum albumin); open and solid arrows show the elution positions of ${ }^{125}$ I-labeled glucagon and glucagon(4-29), respectively. 

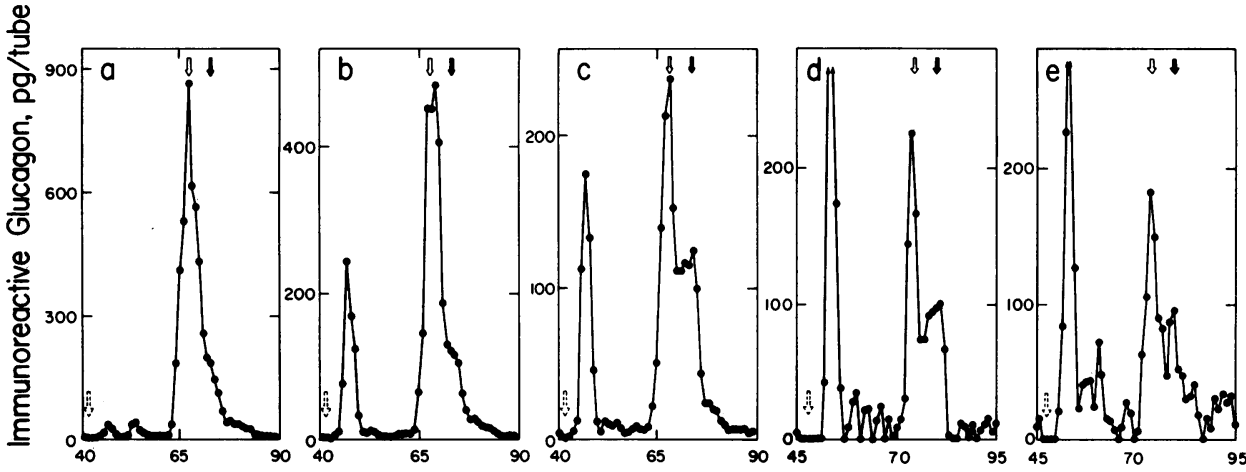

Fraction Number
Figure 9. Gel filtration on Bio-Gel P-6 of immunoreactive glucagon extracted from canine plasma by adsorption to C-18 cartridges. (a) immunoreactive glucagon in plasma from the canine femoral artery taken during a constant, peripheral infusion of glucagon; (b) immunoreactive glucagon in plasma from the pancreaticoduodenal vein in an untreated dog; $(c)$ immunoreactive glucagon in plasma taken from the hepatic vein of the untreated dog studied in panel $b ;(d)$ immunoreactive glucagon in plasma taken from the

renal artery of a second $\operatorname{dog} ;(e)$ immunoreactive glucagon in plasma taken from the renal vein of the untreated dog studied in panel $d$. In all panels, the dashed arrow shows the void volume of the column, as determined by the elution of bovine serum albumin, and open and solid arrows show the elution positions of ${ }^{125}$ I-labeled glucagon and glucagon(4-29), respectively. Antiserum G-15 was used for radioimmunoassay in each case.

rectly returns internalized receptor and ligand to the cell surface, ref. 40 and 41 ), and the relatively lesser contribution of a mechanism involving lysosomes, would account for the release from incubated cells of intact glucagon(4-29).

Our identification of a peptide having the size and immunological properties expected of glucagon(4-29) in the plasma of both man and dogs validates in an important way the conclusion that the glucagon fragment released from hepatocytes into incubation medium in vitro is also released into the extracellular fluid in vivo and that it represents a physiologically significant degradation product of the hormone. Importantly, this glucagon metabolite is distinct from the substance called IRG ${ }^{2000}$ (30) in that the two plasma components elute at different positions during gel filtration and that plasma levels of glucagon(429), unlike those of $\operatorname{IRG}^{2000}(30,31)$, are increased in chronic renal failure. We have further demonstrated in $\operatorname{dogs}(a)$ a positive gradient of this metabolite across the liver, $(b)$ no differential gradient of the metabolite relative to glucagon across the kidney, (c) the poor conversion of glucagon to the metabolite during peripheral infusion of the hormone in somatostatin-suppressed animals, and $(d)$ increased proportionate amounts of both plasma glucagon and glucagon(4-29) in chronic renal failure patients. While we can exclude neither an unlikely inhibitory effect of somatostatin on peripheral glucagon metabolism nor the existence of extrahepatic sites for the production of glucagon(429), our findings identify the liver as an important site for the production of the circulating hormone fragment.

Because approximately one-fourth of the immunorective glucagon exiting the liver in our animal model and appearing in the peripheral circulation in both dogs and man appears to represent glucagon(4-29), and because glucagon(4-29) is fully active in $\mathrm{COOH}$-terminal radioimmunoassays that are most commonly used for the measurement of pancreatic glucagon (cf. ref. 42), the true hepatic clearance of glucagon may have been underestimated: given the total hepatic extraction of immunoreactive glucagon (23\%, ref. 1) and the proportion noted above, the extraction of glucagon plus the conversion of additonal glucagon to the inactive metabolite glucagon(4-29) could account for the effective removal of as much as $42 \%$ of the active hormone reaching the portal circulation. This value is indeed little different from that for the hepatic extraction of insulin (45\%, ref. 1), a hormone for which immunoreactive degradation products apparently do not to circulate in the peripheral plasma $(43,44)$.

\section{Acknowledgments}

We thank Bill Pugh and Amy Addis for performing some of the glucagon radioimmunoassays, Kenneth Polonsky and Silas Brown for assistance in the animal studies, Bruce Given for assistance with C-18 extraction procedures, and Crystal Sherman-Jones for expert assistance in the preparation of the manuscript.

This investigation was supported by grants AM-18347 and AM-20595 from The National Institutes of Health. Dr. Hagopian received support from the Medical Scientist Training Program grant GM-07281.

\section{References}

1. Jaspan, J. B., K. S. Polonsky, M. Lewis, J. Pensler, W. Pugh, A. R. Moosa, and A. H. Rubenstein. 1981. Hepatic metabolism of glucagon in the dog: contribution of the liver to the overall metabolic disposal of glucagon. Am. J. Physiol. 240:E233-E244.

2. Hagopian, W., E. G. Lever, D. Cohen, D. Emmanouel, K. S. Polonsky, W. Pugh, A. Moosa, and J. B. Jaspan. 1983. Predominance of renal and absence of hepatic metabolism of pancreatic polypeptide in the dog. Am. J. Physiol. 245:E171-E177.

3. Terris, S., and D. Steiner. 1975. Binding and degradation of ${ }^{125} \mathrm{I}-$ insulin by rat hepatocytes. J. Biol. Chem. 250:8389-8398.

4. Terris, S., and D. Steiner. 1976. Retention and degradation of ${ }^{125} \mathrm{I}-$ insulin by perfused livers from diabetic rats. J. Clin. Invest. 57:885-896.

5. Hruska, K. A., J. Blondin, R. Bass, J. Santiago, P. Thomas, P. Altsheer, K. Martin, and S. Klahr. 1979. Effect of parathyroid hormone on hepatic glucose release in the dog. J. Clin. Invest. 64:1016-1023.

6. Hoffman, C., J. W. Mars, B. Muller, and D. F. Steiner. 1980. Cultured hepatoma cells as a model system for studying insulin processing and biologic responsiveness. Diabetes. 29:865-874.

7. Carpentier, J.-L., P. Gorden, P. Barazzone, P. Freychet, A. LeCam, and L. Orci. 1979. Intracellular localization of ${ }^{125} \mathrm{I}$-labeled insulin in hepatocytes from intact rat liver. Proc. Natl. Acad. Sci. USA. 76:28032807.

8. Carpentier, J.-L., P. Gordon, P. Freychet, A. LeCam, and L. Orci. 1979. Lysosomal associations of internalized ${ }^{125}$ I-insulin in isolated rat hepatocytes. J. Clin. Invest. 63:1249-1261.

9. Khan, M. N., B. I. Posner, R. J. Kahn, and J. J. M. Bergeron. 1982. Internalization of insulin into rat liver Golgi elements: evidence for vesicle heterogeneity and the pathway of intracellular processing. $J$. Biol. Chem. 257:5969-5976.

10. Burghen, G. A., A. E. Kitabchi, and J. S. Brush. 1972. Characterization of a rat liver protease with specificity for insulin. Endocrinology. 91:633-642.

11. Assoian, R. K., and H. S. Tager. 1982. Peptide intermediates in the cellular metabolism of insulin. J. Biol. Chem. 257:9078-9085. 
12. Misbin, R. I., E. C. Almira, and S. J. Buynitzky. 1983. Insulin metabolism in rat hepatocytes: evidence for generation of an insulin fragment missing a portion of the B-chain involved in receptor binding. J. Biol. Chem. 258:2157-2162.

13. Barazzone, P., P. Gorden, J.-L. Carpentier, L. Orci, P. Freychet, and B. Canivet. 1980. Binding, internalization, and lysosomal association of ${ }^{125} \mathrm{I}$-glucagon in isolated rat hepatocytes. J. Clin. Invest. 66:10811093.

14. Pohl, S. L., H. M. J. Krans, L. Birnbaumer, and M. Rodbell. 1972. Inactivation of glucagon by plasma membranes of rat liver. J. Biol. Chem. 247:2295-2301.

15. Desbuquois, B., and M.-C. Postel-Vinay. 1980. Receptor-mediated internalisation of insulin, glucagon, and growth hormone in intact rat liver: a biochemical study. In Insulin: Chemistry, Structure and Function of Insulin and Related Hormones. D. Brandenberg and A. Wollmer, editors. Walter de Gruyter and Co., New York. 285-292.

16. Hagopian, W. A., and H. S. Tager. 1984. Receptor binding and cell-mediated metabolism of ${ }^{125} \mathrm{I}$-monoiodoglucagon by isolated canine hepatocytes. J. Biol. Chem. 259:8986-8993.

17. Jacobs, S., and P. Cuatrecacas. 1981. Insulin receptor: structure and function. Endocrinol. Rev. 2:251-263.

18. Welton, A. F., P. M. Lad, A. C. Newby, H. Yamamura, S. Nicosia, and M. Rodbell. 1977. Solubilization and separation of the glucagon receptor and adenylate cyclase in guanine nucleotide-sensitive states. $J$. Biol. Chem. 252:5947-5950.

19. Schlengel, W., E. S. Kempner, and M. Rodbell. 1979. Activation of adenylate cyclase in hepatic membranes involves interactions of the catalytic unit with multimeric complexes of regulatory proteins. J. Biol. Chem. 254:5168-5176.

20. Ross, E. M., and A. G. Gillman. 1980. Biochemical properties of hormone-sensitive adenylate cyclase. Annu. Rev. Biochem. 49:535564.

21. Assoian, R. K., and H. S. Tager. 1981. [( $\left.{ }^{125} \mathrm{I}\right)$ iodotyrosyl $\left.{ }^{\mathrm{B} 1}\right]$ insulin: semisynthesis, receptor binding, and cell-mediated degradation of a B chain-labeled insulin. J. Biol. Chem. 256:4042-4049.

22. McDonald, J. K., P. X. Callahan, B. B. Zeitman, and S. Ellie. 1969. Inactivation and degradation of glucagon by dipeptidyl aminopeptidase (cathepsin C) of rat liver. J. Biol. Chem. 244:6199-6208.

23. Hruby, V. J. 1982. Structure-conformation-activity studies of glucagon and semisynthetic glucagon analogs. Mol. Cell Biochem. 44: 49-64.

24. Frandson, E. K., F. C. Grønvald, L. G. Heding, N. J. Johnasen, B. F. Lundt, A. J. Moody, J. Markussen, and A. Vølund. 1981. Glucagon: structure-function relationships investigated by sequence deletions. Hoppe-Seyler's Z. Physiol. Chem. 363:665-677.

25. Wright, D. E., and M. Rodbell. 1979. Glucagon , $_{1-6}$ binds to glucagon receptor and activates hepatic adenylate cyclase. J. Biol. Chem. 254:268-269.

26. Bonnevie-Nielsen, V., K. S. Polonsky, J. B. Jaspan, A. H. Rubenstein, T. W. Schwartz, and H. S. Tager. 1982. Surface receptors for pancreatic hormones in dog and rat hepatocytes: qualitative and quantitative differences in hormone-target cell interactions. Proc. Natl. Acad. Sci. USA. 79:2156-2171.

27. Neville, D. M. Jr. 1968. Isolation of an organ-specific protein antigen from cell-surface membrane of rat liver. Biochim. Biophys. Acta. $154: 540-552$.
28. Jaspan, J. B., and A. H. Rubenstein. 1977. Circulating glucagon: plasma profiles and metabolism in health and disease. Diabetes. 26:887904.

29. Recant, L., P. V. Perrier, S. J. Bhathena, D. N. Danforth, and R. L. Lavine. 1976. Plasma immunoreactive glucagon fractions in four cases of glucagonoma: increased "large glucagon-immunoreactivity". Diabetologia. 12:319-326.

30. Valverde, I. 1983. Heterogeneity of circulating glucagon and glucagon-like immunoreactivity. In Handbook of Experimental Pharmacology. P. J. Lefebvre, editor. Springer Verlag, Heidelberg. 223-244.

31. Soybel, D., J. Jaspan, K. Polonsky, I. Goldberg, E. Rayfield, and H. Tager. 1983. Differential immunoreactivity of plasma glucagon components in man: studies with different glucagon antibodies. J. Clin. Endocrinol. Metab. 56:612-618.

32. Ueda, M., F. W. Robinson, M. M. Smith, and T. Kono. 1985. Effects of monensin on insulin processing in adipocytes: evidence that the internalized insulin-receptor complex has some physiological activities. J. Biol. Chem. 260:3941-3946.

33. Hammons, G. T., R. M. Smith, and L. Jarett. 1982. Inhibition by bacitracin of rat adipocyte plasma membrane degradation of ${ }^{125} \mathrm{I}$ insulin is associated with an increase in plasma membrane-bound insulin and a potentiation of glucose oxidation by adipocytes. J. Biol. Chem. 257:11563-11570.

34. Plas, C., and B. Desbuquois. 1982. Receptor-mediated insulin degradation and insulin-stimulated glycogenolysis in cultured foetal hepatocytes. Biochem. J. 202:333-341.

35. Sonne, O., T. Berg, and T. Christoffersen. 1978. Binding of ${ }^{125} \mathrm{I}$ labeled glucagon and glucagon-stimulated accumulation of adenosine $3^{\prime}: 5^{\prime}$-monophosphate in isolated intact rat hepatocytes. J. Biol. Chem. 253:3203-3210.

36. Bonnevie-Nielsen, V., and H. S. Tager. 1983. Glucagon receptors on isolated hepatocytes and hepatocyte membrane vesicles: discrete populations with ligand- and environment-dependent affinities. J. Biol. Chem. 258:11313-11320.

37. Bregman, M. D., D. Trivedi, and V. J. Hruby. 1980. Glucagon amino groups. J. Biol. Chem. 255:11725-11731.

38. Balow, R., U. Ragnarsson, and O. Zetterqvist. 1983. Tripeptidyl aminopeptidase in the extralysosomal fraction of rat liver. J. Biol. Chem. 258:11622-11628.

39. Hagopian, W. A., and H. S. Tager. 1985. Peptide intermediates in the hepatic processing of glucagon. Diabetes. 34(Suppl. 1):59A.

40. Marshall, S. 1985. Dual pathways for the intracellular processing of insulin. J. Biol. Chem. 260:13524-13531.

41. Marshall, S. 1985. Degradative processing of internalized insulin in isolated adipocytes. J. Biol. Chem. 260:13517-13523.

42. Tager, H. S. 1984. Glucagon-containing and glucagon-related peptides: evolutionary, structural, and biosynthetic considerations. In Evolution and Tumor Pathology of the Neuroendocrine System. S. Falkmer, R. Hakanson, and F. Sundler, editors. Elsevier Science Publishers, New York. 285-311.

43. Shoelson, S., M. Haneda, P. Blix, A. Nanjo, T. Sanke, K. Inouye, D. Steiner, A. Rubenstein, and H. Tager. 1983. Three mutant insulins in man. Nature (Lond.). 302:540-543.

44. Robbins, D. C., S. E. Shoelson, H. S. Tager, P. M. Mead, and D. H. Gaynor. 1985. Products of therapeutic insulin in the blood of insulin-dependent (Type I) diabetic patients. Diabetes. 34:510-519. 